\title{
A Low Cost Remotely Analysis of ECG Signal based on LabVIEW
}

\author{
Walaa Esame Kamel \\ MSc. Student, Benha University \\ Faculty of Engineering Shoubra \\ Department of Electrical \\ Engineering - 108 Shoubra Street \\ Cairo Egypt
}

\author{
Ashraf Hafez \\ Benha University \\ Faculty of Engineering Shoubra \\ Department of Electrical \\ Engineering - 108 Shoubra \\ Street, \\ Cairo .Egypt
}

\author{
Hala Mohamed Abd-Elkader \\ Benha University \\ Faculty of Engineering Shoubra \\ Department of Electrical \\ Engineering - 108 Shoubra \\ Street, \\ Cairo .Egypt
}

\begin{abstract}
Electrocardiography (ECG) is a popular technique that is widely used to detect cardiac problems. One of the difficulties in developed countries is the lack of the number of specialists in heart diseases compared with the number of patients. Another problem is the high cost of ECG devices and medical services. This work helps to minimises the effects of these problems by development of a low cost ECG that can register and analyse the ECG signal of the patient. The ECG graph and the analysed data are sent to a remote expert for diagnosis by utilising diverse of communication technologies. In this work, the Internet is used as a low price and widely available technology. The history of the patient records is also stored in a cloud server. So the solution is characterized by being cheap, easy to use, and efficient for remote usage.
\end{abstract}

\section{Keywords}

ECG Analysis, Arduino, LabVIEW \&IOT

\section{INTRODUCTION}

Cardiovascular diseases (CVDs) are the number one cause of death globally [1]. More people die yearly from CVDs than from any other cause. 17.9 million People died from CVDs in 2016, which is $31 \%$ of all global deaths. Of these deaths, $85 \%$ are due to stroke and heart attack. Developing countries account for more than three quarters of cardiovascular disease deaths. Out of the 17 million premature deaths (under the age of 70) due to non communicable diseases in $2015,82 \%$ are in developing countries, and $37 \%$ are caused by CVDs. Most cardiovascular diseases can be prevented by treating behavioral risk factors such as smoking, injurious diet and corpulence, physical stillness and harmful use of alcohol [1]. Developing countries suffer from the lack of medical services and their high cost. In Egypt, the death from heart disease is five times other countries by 500 cases per 100 thousand Egyptians. CVD's account for $46 \%$ of total deaths in Egypt [1],[2]. CVDs are a frontier public health concern with significant social and economic implications in terms of healthcare needs, lost productivity and premature death [1]. The disease burden caused by CVDs in particular, is further fuelled by adoption of unhealthy lifestyles and eating habits. In fact, the incidence of CVD is fast shifting to the youth; a trend that's specifically prevalent in the capital city of Cairo and underserved urban communities where the lack of the number of specialists in heart diseases comparison with the number of patients [1]. In recent years several communication technologies such as Internet and mobile communication are widely used and their costs are continuously decreased. The advancement of electronic technology decreases the price of sensors and circuits. So, this work exploits these factors to develop a simple and low cost ECG. LabVIEW software is used to detect the ECG signal, reduces noise and extracts the ECG features [3]. The Internet is used as a tool to upload these data to a cloud for a further analysis and diagnosis by an expert [4]. Electrocardiogram (ECG) records electrical activity of the heart. During each heartbeat, a healthy heart has an orderly advancement of depolarization that starts with pacemaker cells in the senatorial node, spreads out through the atrium, passes through the atrioventricular node down into the pack of His and into the Purkinje fibers, spreading down and to the left throughout the ventricles [5]. This organized pattern of depolarization gives rise to the distinctive ECG tracing. For the trained clinician, an ECG transmits a large amount of information about the structure of the heart and the task of its electrical conduction system. Between other things, an ECG can be used to estimate the regularity of heartbeats [6], the size, and position of the heart chambers, the presence of any harm to the heart's muscle cells or conduction system, the effects of cardiac realty, and the function of implanted pacemakers. It is widely applied in the medical field, due to its noninvasiveness and its capability of detecting cardiac diseases. ECG is normally recorded in hospitals or clinical centers in which the patient needs to stay for hours or days. Portable or ECG telemetry devices have enabled patients to monitor their ECG. A normal ECG signal is shown in fig.1 [3] [7].Table (I) presents various components of the ECG signal and their function indications.

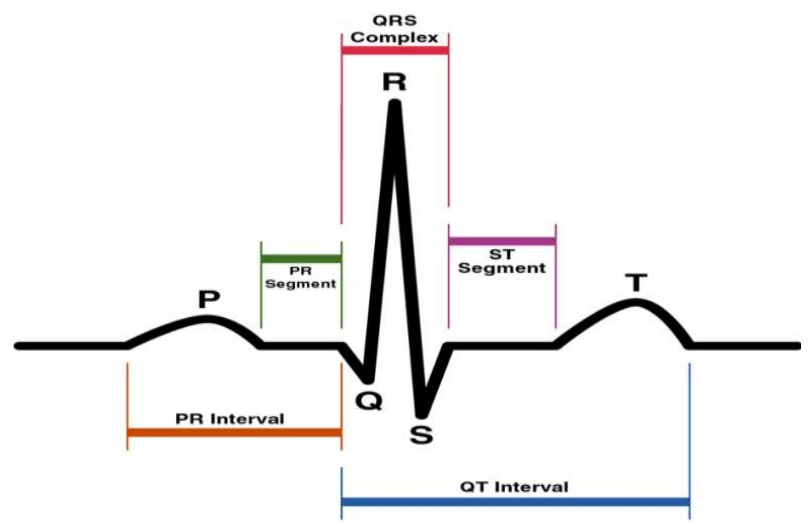

Figure (1) a normal ECG signal 
Table (1) ECG signal components

\begin{tabular}{|c|c|}
\hline P wave & represents the depolarization of the atria \\
\hline PR Interval & $\begin{array}{l}\text { It is a period that begins with the beginning } \\
\text { of the } p_{-} \text {wave and ends at beginning the } \\
\text { complex. } \\
\text { It Is the period of the transmission of the } \\
\text { impulse of the atrium to ventricle. }\end{array}$ \\
\hline QRS Complex & $\begin{array}{l}\text { represents the depolarization of the } \\
\text { ventricles }\end{array}$ \\
\hline ST Segment & $\begin{array}{l}\text { Through which I know whether it is } \\
\text { ischemia and infarction or not through a } \\
\text { point called (J point). }\end{array}$ \\
\hline J point & $\begin{array}{l}\text { Is the junction between the end of QRS and } \\
\text { the beginning of ST segment? }\end{array}$ \\
\hline T wave & $\begin{array}{l}\text { represents the repolarization of the } \\
\text { ventricles }\end{array}$ \\
\hline QT Interval & $\begin{array}{l}\text { Electrically represents the entire ventricle. } \\
\text { It represents the time taken for ventricular } \\
\text { depolarization and depolarization. } \\
\text { The Qt interval is the time from the start of } \\
\text { the } Q \text { wave to the end of the } T \text { wave. }\end{array}$ \\
\hline
\end{tabular}

\section{PROPOSED ECG SYSTEMS}

Figure (2) shows the proposed ECG system block diagram. In the following, the function of each block will be explained. ECG electrodes sense the electric activity of the heart and transfer this activity to the ECG Arduino shield that's used for capturing, filtering, and amplifying the ECG signal [8]. Arduino board is used to transfer the ECG signal to a laptop. LabVIEW software is used to analyses the ECG signal to extract its numerical features. Internet is used to send the ECG signal with its associated features to an expert for diagnosis. The ECG signal records are stored on the cloud to be used by an expert to track the history of the case.

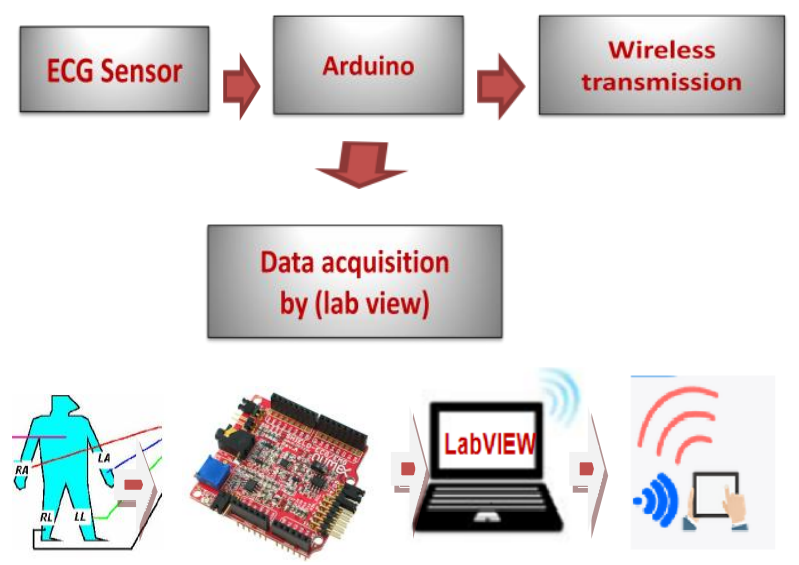

Figure (2) Proposed System

\subsection{Labview ECG signal analysis}

The ECG signal is analysed in several steps as shown in figure (3). First, 30 seconds captured ECG signal data is saved in an excel file. This excel file is converted to TDMS format [3] to be appropriate for analyses in the LabVIEW environment. Two digital filters are used to adapt the ECG signal. The first filter is a low pass filter which is responsible for removing both the high frequency muscle artefact and the external interference. The second filter is a band pass filter which is used to remove disturbances caused by respiration and displacement of electrodes [9]. Finally, the ECG features such as the QRS complex, P wave, T wave, and ST segment are extracted. These features can be displayed or saved for later retrieving.

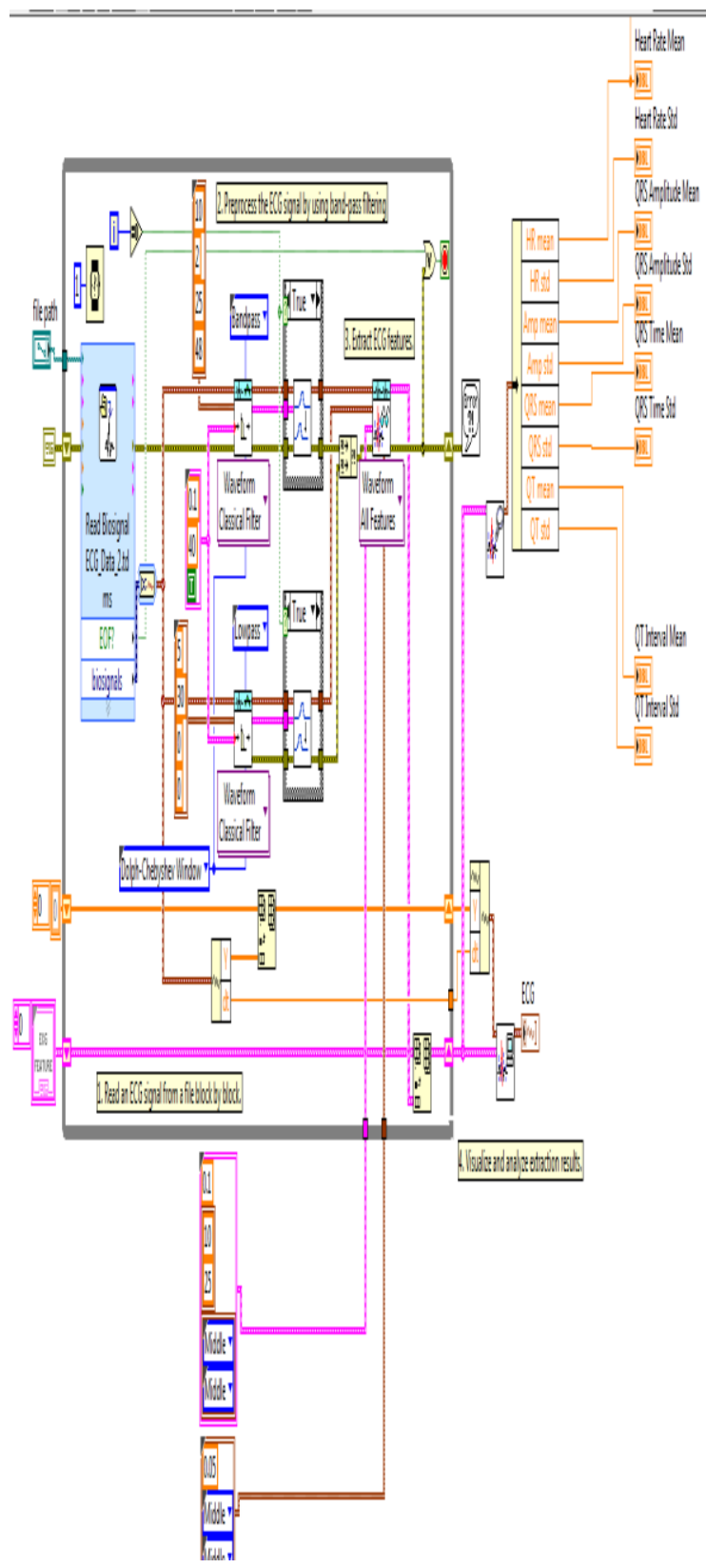

Figure (3) LabVIEW ECG signal analysis

\subsection{Performance test and practical work}

The performance test for the proposed work is divided into two main PARTS. Firstly, a predetermined data for different cases[10] is incorporated to the LabVIEW program at which data analysis is carried out. The analysis results of normal heart beat and quick heart beat s cases are show in figures (4) \& (5) respectively. Typical ECG signatures are shown in table. 2 and the heartbeats of Healthy Adults usually range from 60 to $100 \mathrm{PPM}$ of for when the person is in a state of 
REST [3] . The equation to calculate heart rate is given by [11] Heart Rate $=(\mathbf{1} / \mathbf{R R}$ Interval in sec. $) * \mathbf{6 0}$

Table (2) Typical ECG signatures for clinical use [12].

\begin{tabular}{|c|c|c|}
\hline $\begin{array}{c}\text { Clinical signature } \\
\text { Typical values } \\
\text { (unit) Nominal } \\
\text { limits (unit) }\end{array}$ & $\begin{array}{c}\text { Clinical signature } \\
\text { Typical values } \\
\text { (unit) Nominal } \\
\text { limits (unit) }\end{array}$ & $\begin{array}{c}\text { Clinical signature } \\
\text { Typical values } \\
\text { (unit) Nominal } \\
\text { limits (unit) }\end{array}$ \\
\hline P width & $110 \mathrm{~ms}$ & $\pm 20 \mathrm{~ms}$ \\
\hline T width & $180 \mathrm{~ms}$ & $\pm 40 \mathrm{~ms}$ \\
\hline PR interval & $120 \mathrm{~ms}$ & $\pm 20 \mathrm{~ms}$ \\
\hline QRS width & $100 \mathrm{~ms}$ & $\pm 20 \mathrm{~ms}$ \\
\hline QT interval & $400 \mathrm{~ms}$ & $\pm 40 \mathrm{~ms}$ \\
\hline P amplitude & $0.15 \mathrm{mV}$ & $\pm 005 \mathrm{mV}$ \\
\hline T amplitude & $0.3 \mathrm{mV}$ & $\pm 0.2 \mathrm{mV}$ \\
\hline QRS amplitude & $1.2 \mathrm{mV}$ & $\pm 0.5 \mathrm{mV}$ \\
\hline
\end{tabular}

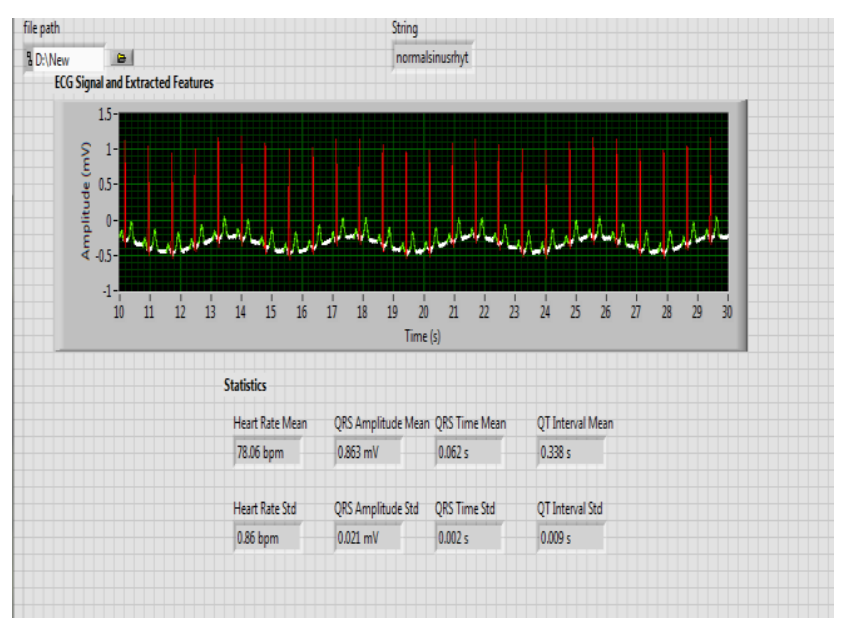

Figure (4) Predetermined Normal heart beat

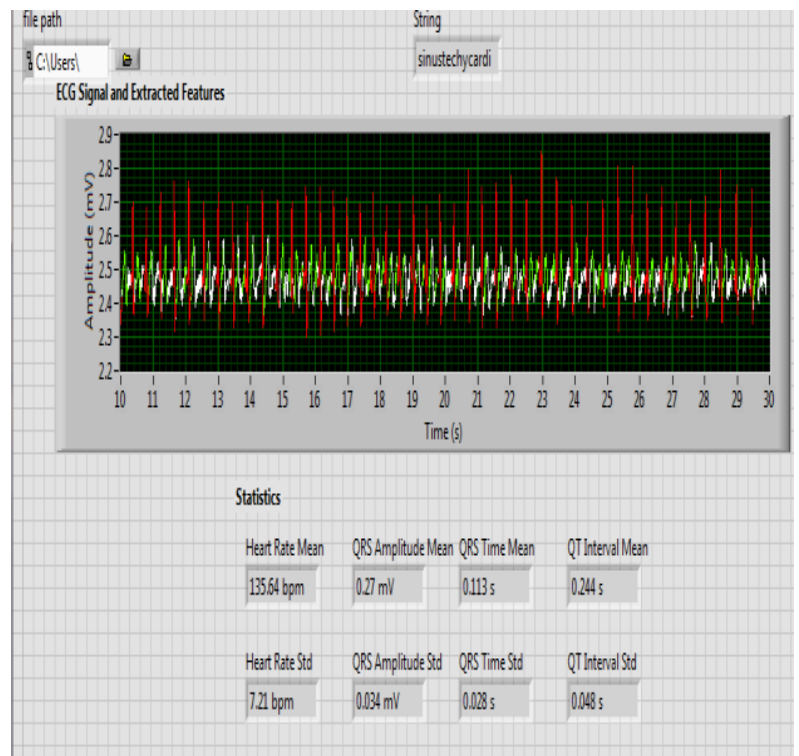

Figure (5) A Predetermined quick heartbeat
Secondly, ECG signal recordings are taken directly from real persons. These recording are analysed by LabView program. These recordings with their associated analysis results are shown in figures (6) \& (7) for normal heartbeat case and figs (8) \& (9) for a quick heartbeat.

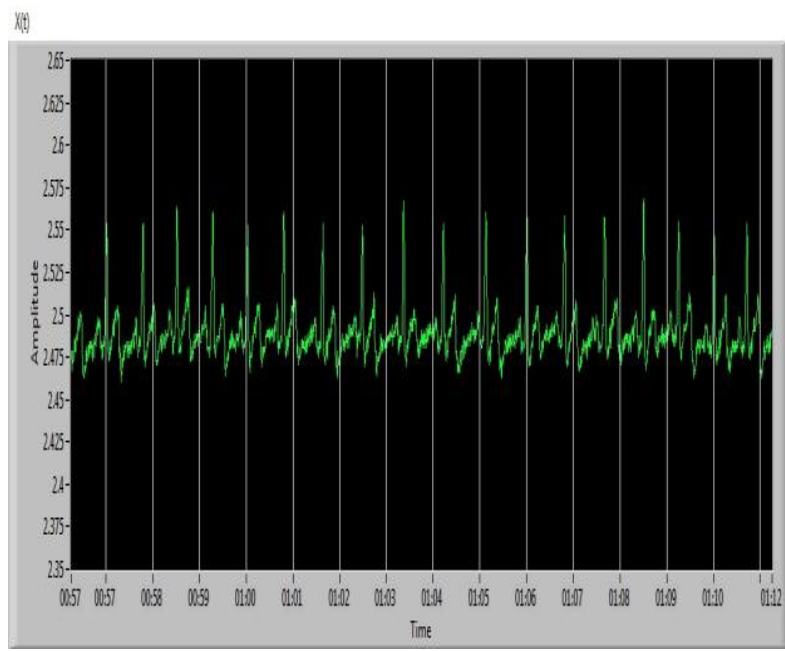

Figure (6) Normal heartbeat

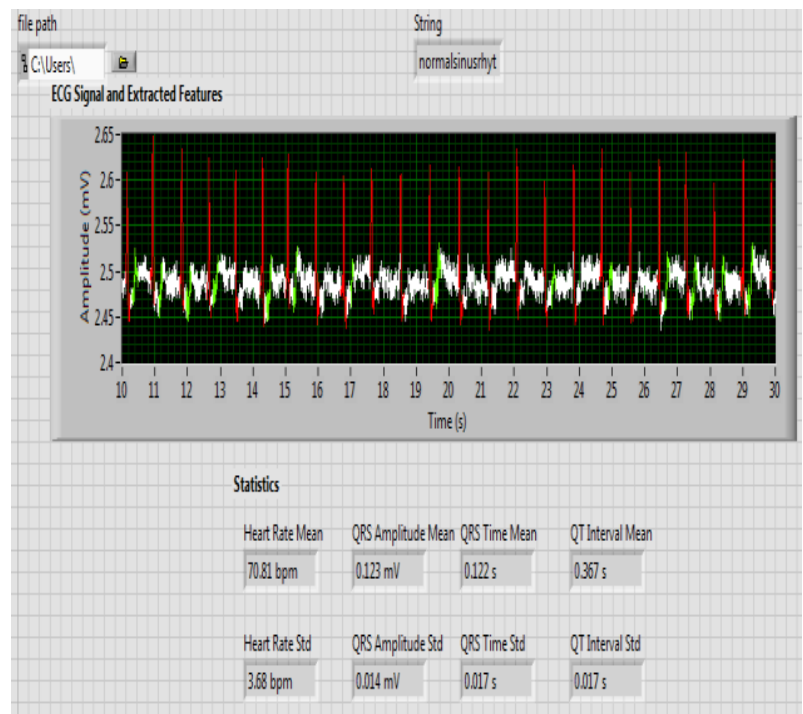

Figure (7) Normal heartbeat Analysis

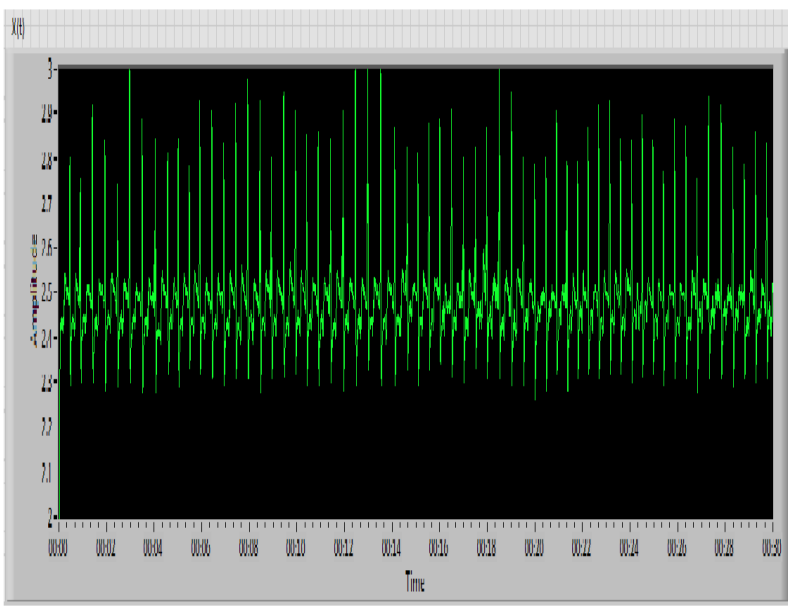

Figure (8) Quick heartbeats 


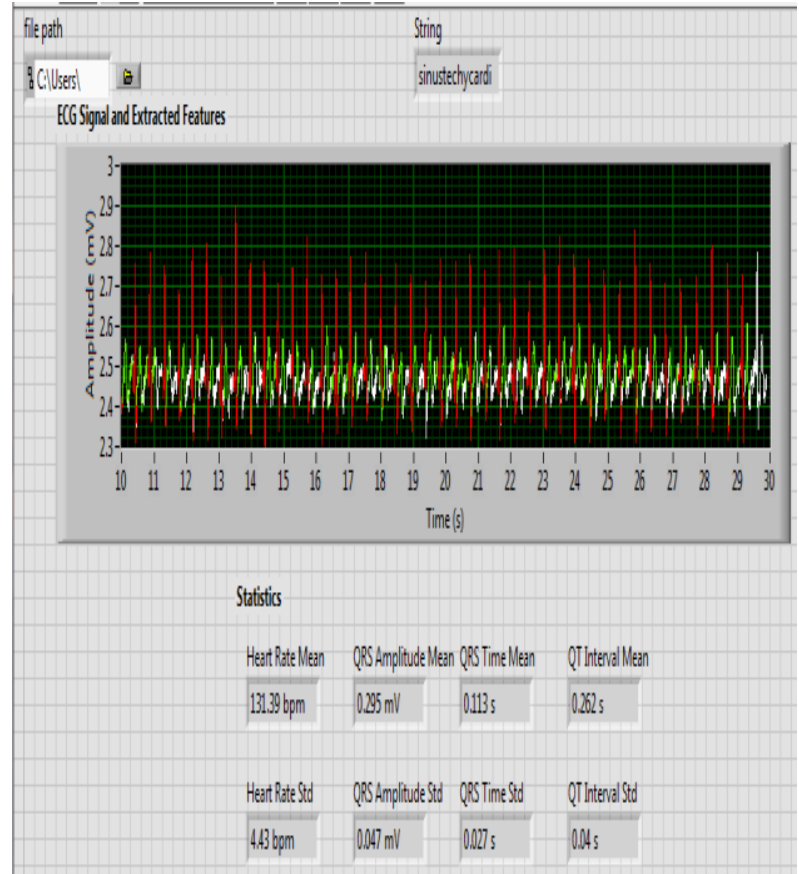

Figure (9) Quick heartbeats Analysis

\section{INTERNET DATA UPLOAD}

Patient ECG recordings and the signal analysis results are uploaded to a cloud server. The patient doctor can access these data for diagnosis purpose [13],[14] . A web site has been built and its home page[15] is shown in figure.10 where several options are available. From patient option, either registering a new patient or presenting records of a registered patient is selected.

Home Patient Contact Us logout AboutUs

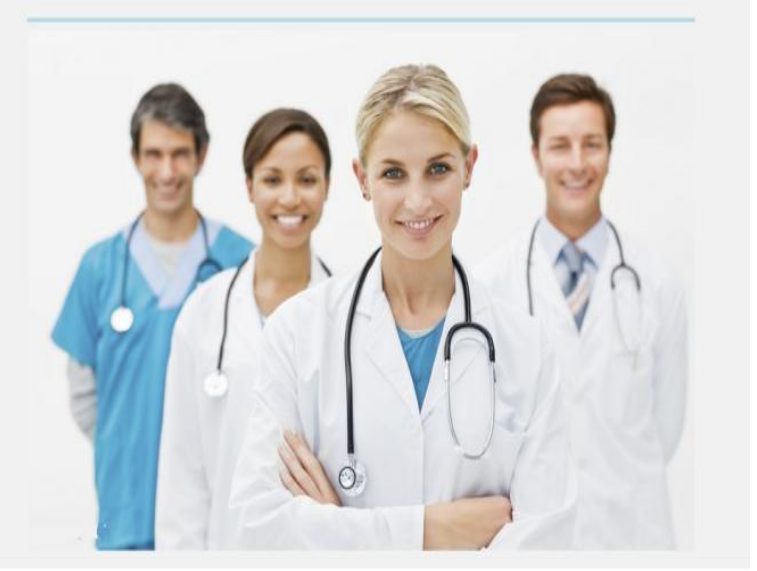

Figure 10 Website Home Pages

New patient page is shown in figure. 11 where the patient data is entered (Name, Address, Phone, Birthday, User name, Password).

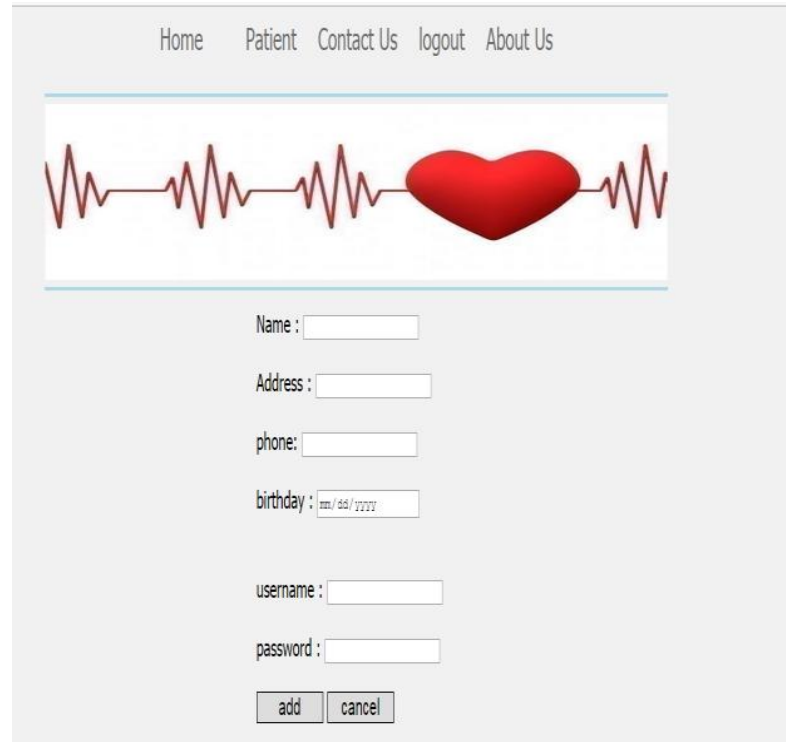

Figure 11 New patients Page

Recorded Patients page is shown in figure. 12 This Page displays a Table that lists all the patients in the system and their data (ID, Name, Address, Phone, Age, and Start Date of their registration).

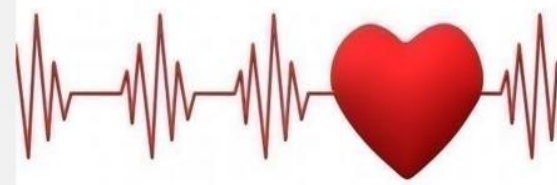

\begin{tabular}{|c|c|c|c|c|c|c|c|c|}
\hline & & & $\operatorname{Sot} B / 1 D$ & & search & & & \\
\hline ID & Name & Adtress Rate & Phone & age & StartDate & Resilts & Repout & Ealit \\
\hline 1 & vaber & stowo & 010 & 3 & $\begin{array}{l}201808399 \\
1639: 14\end{array}$ & Results & report & merbege \\
\hline 5 & ail|cssn & (a)- $13 x$ dit) & 012 & 15 & $\begin{array}{l}2018444 \\
17: 4: 11\end{array}$ & Pasilts & repont & marbege \\
\hline 6 & matmoud & sthoro & 010 & 32 & $\begin{array}{l}20: 8444 \\
17: 48: 17\end{array}$ & Realls & repout & maroge \\
\hline 7 & absiaxd & sthes & 010231453 & 0 & $\begin{array}{l}20881015 \\
224949\end{array}$ & Rasils & repoot & marage \\
\hline 8 & matmoud & dadorer & 01022106033 & 2015 & $\begin{array}{c}2018101717 \\
160010556\end{array}$ & Resilts & repowt & marbege \\
\hline 9 & $m i s$ & ghtgi & 00137865 & 0 & $\begin{array}{l}20: 907: 24 \\
06: 1537\end{array}$ & Rasults & repoot & marage \\
\hline
\end{tabular}

\section{Figure 12 Show Patient Web Pages}

From the table you can access a certain patient historical records (Heart beat rates, ECG signal graph and the result of ECG signal analysis) as show Figure. 13 


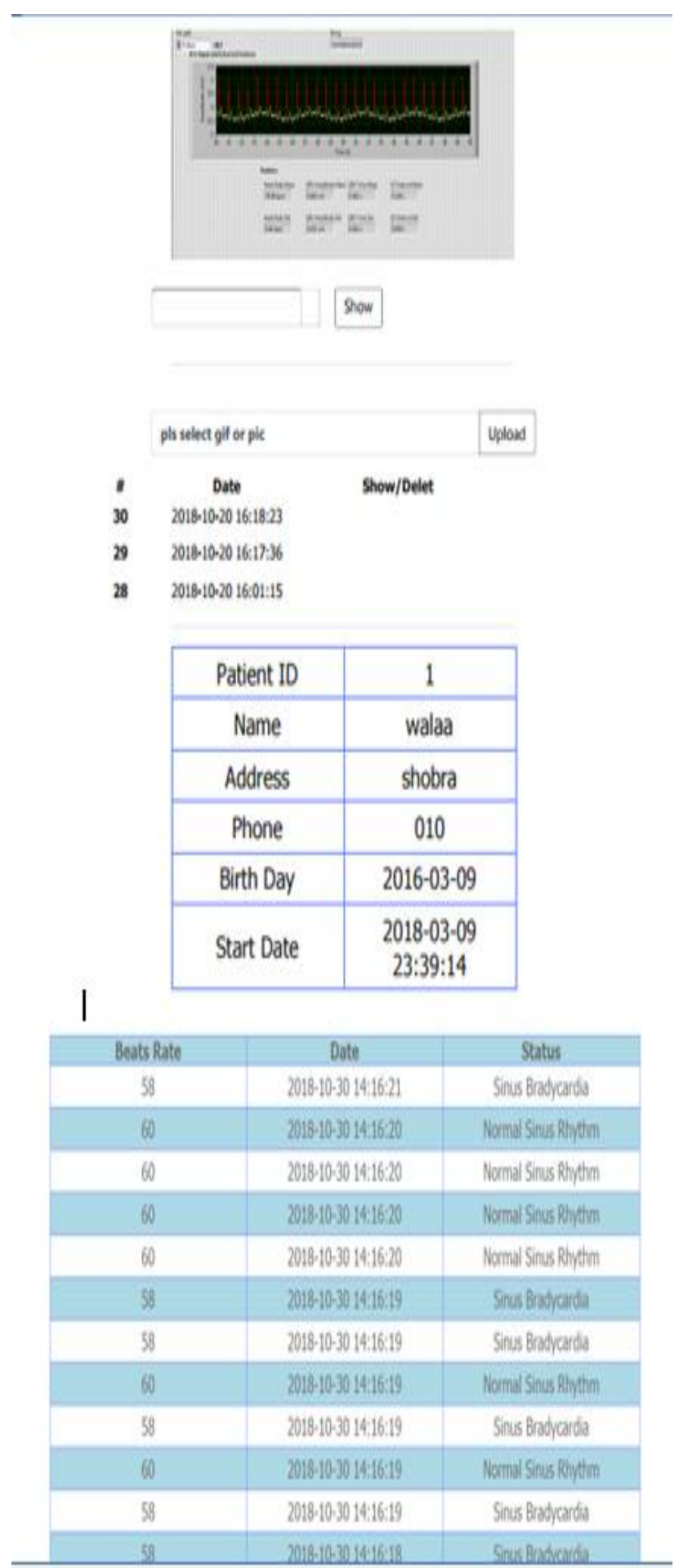

Figure 13 Records for a patient

\section{CONCLUSIONS}

In developing countries, the shortage of the number of skilled experts compared to population and the low economic income make a difficulty to provide health care services. The Cardiovascular diseases are the first cause of the globally death. The ECG is a vital and expensive tool for diagnosis and usually used in hospitals and clinical centers. Patients need to travel from remote location for this purpose. This work is an effort to tackle this problem by developing a low cost ECG system that can capture, analyze, and transfer ECG signal to a clinical expert remotely. The low cost is due to the use of a popular hardware which composed of an Arduino board and an ECG shield. LabVIEW software is used for ECG signal analysis. An Internet web site is constructed to upload, present, and store the ECG signal and its associated features. This helps in fast diagnosis especially for serious cases. The system can be adapted to use other popular communication technologies such as mobile communication. In the future, this system will be developed for preliminary automatic diagnosis.

\section{REFERENCES}

[1] http://origin.who.int/cardiovascular_diseases/en/.Accesse d in 3 March 2019.

[2] http://www.healthdata.org/. Accessed in 3 March, 2019.

[3] Jain, S. and P. Kumar. LABVIEW based expert system for Detection of heart abnormalities. in 2014 International Conference on Advances in Electrical Engineering (ICAEE). 2014. IEEE.

[4] Bamarouf, F., et al. Cloud-based real-time heart monitoring and ECG signal processing. in 2016 IEEE SENSORS. 2016. IEEE.

[5] Mou, J.R., et al. A new approach of noise elimination methodology for ECG signal. in 2017 International Conference on Electrical, Computer and Communication Engineering (ECCE). 2017. IEEE.

[6] Akilandeswari, K. and R. Sathya, Feature extraction of ECG signals for early detection of heart arrhythmia. International Journal of Advanced Research in Computer and Communication Engineering, 2014. 3(12): p. 87118713.

[7] HU, S.-y., et al, A DETECTION AND ANALYSIS SYSTEM OF ECG SIGNALS BASED ON WAVELET ENTROPY. 21

[8] https://www.olimex.com, Accessed in 4 April 2019.

[9] Wadhwani, A. and M. Yadav, Filtration of ECG signal by using various filter. International Journal of Modern Engineering Research (IJMER), 2011. 1(2): p. 658-661.

[10] http://www.ni.com/example/27944/en/ Accessed in 29 September 2018.

[11] Islam, M., et al., Study and analysis of ecg signal using matlab \&labview as effective tools. International journal of Computer and Electrical engineering, 2012. 4(3): p. 404.

[12] Gupta, R., M. Mitra, and J. Bera, ECG acquisition and automated remote processing. Vol. 20. 2014: Springer.

[13] Deshpande, U. and M.A. Kulkarni, Iot based real time ecg monitoring system using cypress wiced. International Journal of Innovative Research in Science, Engineering and Technology, 2017.

[14] Hassanalieragh, M., et al. Health monitoring and management using Internet-of-Things (IoT) sensing with cloud-based processing: Opportunities and challenges. in 2015 IEEE International Conference on Services Computing. 2015. IEEE.

[15] http://hearty.totalh.net/showPatient.php , Accessed in 1 MAY, 2019. 